\title{
Sobre las relaciones económicas y políticas entre China y Colombia
}

\author{
Entrevista a Matt Ferchen*
}

\author{
Por Richard Benavidez \\ Politólogo, Universidad Icesi \\ (richard-prada@hotmail.com)
}

Richard Benavidez (RB): El año pasado Colombia firmó el TLC con Corea. Se está haciendo mucha presión para que algo similar se haga con China. Así mismo, el presidente de Colombia está muy interesado en realizar acuerdos con varios países de Asia, entre los que se destaca China. Cuando se habla de la situación económica de Latinoamérica es inevitable hablar de China. Sin embargo, Ariel Armony, de la Universidad de Miami, dice que las demandas de los chinos benefician principalmente a productores de commodities en los países

* Traducción al español por Alexandra Ocampo. de Latinoamérica, tales como Brasil, Chile, Argentina y Perú. Desde su perspectiva ¿Cuál es la importancia de Colombia como un actor o socio comercial?

Matt Ferchen (MF): Colombia se ajusta y no, simultáneamente, a la idea que ustedes acaban de mencionar de Ariel Armony, acerca de que las relaciones comerciales se basan principalmente en la exportación de commodities. Se ajusta porque, en mi entendimiento, lo que China mayormente está haciendo en términos de inversión y lo que Colombia ofrece es el mismo tipo de cosas, entre estas: recursos naturales, petróleo, 
"Colombia, en este sentido, tiene un desafio, porque si se tiene un sistema legal que es relativamente fuerte (...) y que, a pesar de los problemas, tiene un sistema democrático relativamente estable y una economía estable (...) Colombia debería decirle a China 'ustedes deberían querer desarrollar relaciones con nosotros","

minería e inversión exterior, como la que China hace en otras partes del mundo, en infraestructura, tal vez en proyectos de autopistas, represas hidroeléctricas, ese tipo de cosas. Entonces, eso se ajusta a la manera en la que China está haciendo negocios con otros países de Latinoamérica.

Sin embargo, Colombia, desde el punto de vista de los recursos naturales, sin duda, no es lo mismo que otros principales exportadores de Latinoamérica. No es Brasil con sus inmensas cantidades de hierro, no es Chile con el cobre, no es Argentina con la soya, ni Perú, y ni siquiera Ecuador con los acuerdos petroleros. Aunque parece que el petróleo se ha convertido en una importante parte del comercio con China; la compañía de petróleo nacional de Colombia está haciendo un buen trabajo al respecto.

Pero la economía colombiana, desde mi entendimiento, ha sido más balanceada. Si no se tiene en cuenta el tema de la droga, se observa una historia muy fuerte de desempeño macroeconómico, también una buena interrelación con los Estados Unidos. En términos de políticas económicas propias es mas balanceada, en ciertos sentidos, que otros 
países de la región que han tenido ambivalencias y este tipo de cosas. Además, la economía no se basa en la exportación de commodities, aunque tiene algo de ello, también se fundamenta en petróleo, café y drogas. En este sentido, no creo que se ajuste porque existe un tipo de economía diferente, una con un sistema legal muy fuerte -hablando en términos relativos-, y en comparación con los vecinos esto una fortaleza para Colombia en sus relaciones con China. Es una fortaleza, en el sentido de que un sistema legal fuerte debería ser atractivo, porque se sabe claramente cuáles son las reglas del juego en la inversión, hay garantías cuando se firma un contrato y cuando se implementa. Ello debería ser una fortaleza, y yo pienso que al largo plazo lo será. Pero en el momento, China está muy contenta haciendo tratos con otros líderes, en especial, con el vecino de al lado, Venezuela, que no ofrece nada de esto -no hay seguridad en el sistema legal-. Pero en Venezuela están muy felices por darle a China acceso preferencial al mercado petrolero y a otro tipo de proyectos.

Según lo dicho, Colombia se ajusta -más o menos- y tiene algunas ventajas, pero probablemente debe tomarse algo de tiempo para pensar cuidadosamente en ello, especialmente con Venezuela y Ecuador como vecinos, porque China está haciendo tratos con estos líderes y está muy feliz. Chávez también está muy feliz.

RB: Bolivia estaba trabajando con China haciendo las conexiones para el sistema de comunicación celular. Hicieron torres en tierras donde no había nadie. No hay agua pero hay conexión a celular. No hay una buena infraestructura para viajar por tierra, no hay avenidas, pero tienen la conexión celular que hizo China. ¿Eso se ajusta al pensamiento social sobre lo que un gobierno debería hacer por la gente?

MF: es una muy buena pregunta: ¿Quién crees que es el responsable? El desarrollo en la infraestructura es algo que se necesita en la región, tal vez no el desarrollo de la conexión celular, aunque ello puede beneficiar a la población en ciertos aspectos como tener mayor tecnología a un mejor precio, pero tal vez no es la prioridad. Pero el desarrollo de la infraestructura es algo en lo que China es muy bueno, ellos quieren hacerlo, se necesita y hay organizaciones a nivel regional como el Banco Interame- 
ricano de Desarrollo, del cual China es parte en el momento, que están interesados en ello. Entonces China es parte de esa organización, contribuye con dinero y, si organizaciones como el BID y los gobiernos nacionales proponen proyectos prioritarios, que en realidad reflejan lo que se necesita, creo que China podría estar de acuerdo con estos. No creo que China diga"ustedes necesitan algo que nosotros les vamos a decir que es". Yo creo que China puede estar de acuerdo con varios proyectos, pero las prioridades tienen que surgir de los gobiernos nacionales o este tipo de organizaciones que traspasan las fronteras.

RB: Entrando a otro tema, Latinoamérica se conoce por su riqueza en tanto a sus recursos medio ambientales, en este sentido, que implicaciones podrían entreverse al respecto por de la demanda de la clase media de China. Hemos escuchado que existen verdaderos problemas sobre el medio ambiente en este país. Queremos saber si existen políticas que protejan el medio ambiente e indagar, en general, si conoce algo de la política medioambiental china.

MF: De hecho, creo que esta es una de las cosas que los gobiernos locales deberían tener en cuenta. Medio ambiente en términos de seguridad de los trabajadores y, especialmente en países como Bolivia, Ecuador y Perú, donde hay una mayor población indígena que se encuentra en las tierras en que se interesan los inversores mineros o donde se va a realizar la infraestructura. Todos estos problemas requieren de reglas locales fuertes, y esto no solo aplica para los chinos, sino para cualquier industria.

Yo creo se debería asumir que los chinos son como cualquier otro inversor extranjero, pero cincuenta o cien años antes, cuando nadie se preocupaba por el medio ambiente. El público de China no se puede involucrar como el público de otros países, como EEUU o Europa, de donde provienen la mayoría de compañías. En los últimos cincuenta años han surgido muchas reglas sobre los temas de medio ambiente, seguridad de los trabajadores y corrupción. Por ejemplo, bajo el gobierno de Obama, en los EEUU, han sido muy estrictos en implementar reglas anticorrupción en los negocios en el extranjero. En este sentido, lo que se debe hacer es analizar como China implementa las políticas medioambientales, de seguridad de los trabajadores y de corrupción en el ámbito domestico. Así, se observa 
que existen enormes problemas en China, ellos están acostumbrados a que en China no se protejan este tipo de cosas y, si ellos van a otras partes, actuaran consecuentemente. Ellos saben que es malo para su reputación el que una compañía suya lo haga, pero esto es problema de los gobiernos locales. Entonces, puede ser que Colombia tenga mejores reglas para el ambiente y para la inversión que otros países vecinos, pero China va a elegir a los vecinos.

RB: ¿Estas políticas que no propenden por la protección del medio ambiente, ni por la seguridad de los trabajadores, son las que les permiten a los chinos hacer las cosas más baratas y ser muy competitivos? ¿Qué opina sobre la tensión existente entre estos intereses comerciales y económicos y la política social en china?

MF: Algunas de las personas son abusivas, pero la gente lo hace voluntariamente porque su vida anteriormente era horrible. Ellos vivian en el campo donde no había nada para hacer, eran pobre, entonces la gente voluntariamente se ha movido a trabajar en este tipo de trabajos.
RB: Entonces, se debe pensar estos problemas como una persona de China, porque no es lo mismo pensarlo desde acá, desde donde se ven todos los problemas. Si se analiza desde esa perspectiva, se pueden observar las oportunidades que esto significa para la gente y como se mejoran sus vidas en comparación con el pasado. Pero ¿qué sucede cuando salen de China?

MF: Es una muy buena pregunta. Es difícil saberlo, en especial con los que vienen a Latinoamérica porque este es un fenómeno muy nuevo. Existen estudios sobre compañías y gente de China en África, los números son muy grandes, la gente vive en comunidades en donde no es muy fácil acceder. En este sentido es una pregunta muy interesante. Pero alguien me conto que existía un proyecto, aquí en Colombia, en donde trajeron gente de China porque querían trabajar las 24 horas, y tenían el turno del día y el turno de la noche, pero los obreros locales no lo querían hacer. Entonces los chinos trajeron sus propios obreros.

RB: Mucha gente dice que los países latinoamericanos deben preservar sus propios intereses y promover las re- 
laciones bilaterales. ¿Qué debería hacer Colombia para prevenir las consecuencias negativas de las políticas chinas?

Ferchen: Costa Rica tuvo, más o menos, esta oportunidad pero no creo que la esté aprovechando. Costa Rica tiene una larga historia de ser un país democrático y de tener una economía relativamente buena y buenas políticas de desarrollo económico. La mayoría de sus vecinos de Centroamérica han tenido problemas donde a Costa Rica le ha ido bien. Costa Rica empezó sus relaciones bilaterales con China en 2007, donde firmaron un Tratado de Libre Comercio y, en cierto sentido, tuvieron la oportunidad de sustentar este en una fuerte tradición democratiaca en las políticas económicas. Ahora, que están cambiando las relaciones diplomáticas con Taiwan, tuvieron la oportunidad de decir estamos orgullosos de esta tradición, no tenemos fuerzas militares, y estamos felices de tenerlos aquí y hacer esto con ustedes. Uno no quiere ser confrontacional, pero puede estar orgulloso de su sistema, de un sistema legal fuerte y democrático que ha funcionado bien y es estable.

Entonces, me parece que Colombia, en este sentido, tiene un desafío, porque si se tiene un sistema legal que es relativamente fuerte, con cierta independencia judicial y que, a pesar de los problemas, tiene un sistema democrático relativamente estable y una economía estable, ello debería ser un punto fuerte y Colombia debería decirle a China "ustedes deberían querer desarrollar relaciones con nosotros”. Pero ¿Cómo se hace esto? Ese el reto. Porque si ellos van donde los vecinos que no tiene unas políticas muy fuertes, por ejemplo, si van donde Chávez, donde él solo gobierna y no le importa el sistema democrático, como si se hace en Colombia.

Entonces, el problema recae en cómo se hace esto de una manera que no se sea confrontacional, y al tiempo resalte el orgullo sobre estas circunstancias que son algo que ustedes deberían querer tener en cuenta en otros países y algo que deberían valorar.

RB: Pero, creemos que Costa Rica fue estratégica, tal vez ese fue el costo que debieron asumir por tener una relación indirecta con Norteamérica.

MF: Es cierto, también es estratégico porque doce de los países que han reconocido a Taiwan están en el Caribe y en Centroamérica, entonces, ellos querían tener un país que estuviese en el 
medio de esto y tal vez crear un ejemplo. Otra cosa que Colombia podría hacer de manera muy práctica con el nuevo TLC con EEUU, de igual forma que lo hizo Costa Rica, es convertir este TLC en un factor atractivo muy fuerte para atraer la inversión china.

RB: Hemos analizado noticias de la $\mathrm{BBC}$ por un periodo de un mes y dicen que los discursos de China son muy diplomáticos y que este año el incremento en el presupuesto militar es muy alto, lo cual preocupa mucho a EEUU y a la Unión Europea. En este contexto ¿cómo debería percibir Latinoamérica este incremento en el presupuesto militar de China y las políticas ofensivas y defensivas de China?

MF: No soy un experto en seguridad y no presto mucha atención a ello, aunque tengo algunos colegas que si lo hacen, y trabajan en ello, porque es un asunto muy importante. Sin embargo, pienso que deberíamos esperar incrementos en los gastos militares chinos por ser una potencia en ascenso. Pero, el otro lado de ello es mayormente local, y se puede apreciar en términos de ambición militar y la posibilidad de un verdadero uso del hard power o de una expansión de China, que tiene actualmente un conflicto en su zona suroriental por el mar con Japón, con quien las relaciones se encuentran mal, y con Filipinas y Vietnam. Así mismo, de manera más leve, con India porque son competidores y tienen una historia de conflictos por fronteras.

Además, China tiene fronteras con Afganistán y con Pakistán, entonces también tiene preocupaciones locales por los revolucionarios islámicos que quieren su propio territorio dentro de China. Entonces, creo que la mayoría de las ambiciones militares de China, por ahora, son locales y también atadas a los EEUU, que han reorientado su política exterior hacia Asia oriental, y ello significa para China mantener los cielos abiertos. Pero en el mismo modo en que China respeta a los EEUU, quiere que este país, y otros asiáticos, respeten el rol de China como líder natural, histórico y renovado. No obstante, la mayoría de países asiáticos están felices de hacer negocios con China, pero están preocupados porque China use su influencia política y militar para obtener sus recursos, entonces, pienso que la historia militar está en Asia, no en Latinoamérica. Tal vez vendan armas a Venezuela, aunque creo que Rusia es un mayor con- 
tribuidor en términos de venta de armas. Creo que para China es una prioridad las relaciones relativamente buenas que tiene con EEUU. No considero que China se comporte militarmente activa o provocativamente al expandir sus acciones, a menos que se hagan acciones militares en su contra.

Algo interesante para analizar ahora es el caso de la intervención en Libia. En este sentido se debe preguntar ¿Cuántos chinos hay en Venezuela en estos momentos? Deben de haber muchos. Y si se genera caos por cualquier razón, especialmente en una Venezuela post-Chávez o por medidas militares o por cualquier otra cosa ¿qué ocurriría con aquellas personas que son antiChávez? Mirarían a los chinos allí y dirían: "China apoyaba a Chávez. No nos gusta Chávez, entonces no nos gustan los chinos", y ya hay una gran cantidad de violencia y secuestros. ¿Qué tal si los chinos quedan atrapados si algo como esto ocurre? Teniendo en cuenta que no sabemos cuántas personas hay allí. Si China se sigue involucrándose más y más, y si sigue habiendo más inmigrantes chinos, la situación podría a ser peor, como en el caso de Libia, en el cual tuvieron que rescatar a más de 30.000 personas, aunque no afirmo que vaya a haber una crisis de esta magnitud.

Otra cuestión es la nacionalización, por ejemplo, de la compañía de petróleos española en Argentina. ¿Qué sucedería si las compañías chinas se nacionalizaran? Tal vez en ese caso habría una respuesta militar, también podría haberla por razones humanitarias, o en el caso de un desastre natural, entonces cual sería el rol que deberían ejercer las fuerzas militares y cuál sería el impacto global. Esto es algo que hay que pensar.

RB: ¿Por qué China es un tema tan importante en la actualidad?

MF: La razón por la cual hablamos de China, diez años atrás no lo hubiéramos hecho, es algo muy nuevo, y se basa en las cosas de las que ellos carecen, por ejemplo, los recursos naturales que poseen los países latinoamericanos, y creo que se continuará extendiendo a la agricultura donde, aunque en estos momentos no sea muy fuerte, existen intereses. En este sentido, China continuará siendo un actor relevante, aunque esto puede cambiar un poco. No obstante, el problema de la producción de comida va a hacer que China vuelque su mirada hacia Latinoamérica. 
Por otra parte están los mercados, en especial en los últimos cinco o diez años. A muchas economías en Latinoamérica les está yendo relativamente bien, en especial en comparación con Europa o los EEUU, y tienen un grupo de consumidores en constante expansión que pueden comprar las cosas hechas en China. Por ejemplo, estuve hablando con productores de motos en China el año pasado y ellos están muy entusiasmados y consideran una necesidad estar en los países de Latinoamérica, en los cuales hay gente que ahora tienen una mayor capacidad adquisitiva y donde los chinos ingresan con productos relativamente baratos, como las motos, que pueden no ser las mejores pero funcionan muy bien. Entonces pienso que, como las cosas no van bien en el mercado europeo y estadounidense, los chinos ven a la región como un lugar en el cual sus compañías pueden vender. Aunque el mercado chino es enorme, ambas cosas sucederán, ellos necesitarán recursos y querrán vender cosas. 